\title{
A PUZZLE ABOUT WITHHOLDING
}

\author{
By JOHN TURri
}

This paper presents a puzzle about justification and withholding. The puzzle arises in a special case where experts advise us to not withhold judgment. My main thesis is simply that the puzzle is genuinely a puzzle, and so leads us to rethink some common assumptions in epistemology, specifically assumptions about the nature of justification and doxastic attitudes. Section I introduces the common assumptions. Section 2 presents the puzzle case. Section 3 assesses the puzzle case. Section 4 explains the choice we're faced with. Sections 5 and 6 consider and reject some proposed solutions, and in the process refine and clarify the choice we're faced with. Section 7 considers and rejects a miscellany of different proposed solutions.

\section{GOMMON ASSUMPTIONS}

The puzzle I will present arises in acute form if we accept three common views in epistemology. (In the end, it seems to arise if we accept only two of these, and arguably arises if we accept only one of them; more on that later, in sections 5 and 6.) I don't say that the puzzle arises only if we hold these three views. I think there's something here to be accounted for regardless, but for rhetorical purposes I choose to present it in the context of common assumptions.

The first view is Triad, which says that there are only three doxastic attitudes - belief, disbelief, and withholding — and that once you've considered a proposition, there are, intellectually speaking, only three options open to you: you either believe it, disbelieve it, or withhold judgment. Triad is widely accepted in contemporary epistemology, ${ }^{1}$ and was held by earlier philosophers too (e.g. Sextus Empiricus).

${ }^{\mathrm{I}}$ e.g., Ernest Sosa, Knowledge in Perspective (Cambridge UP, I99I), Roderick Chisholm, Theory of Knowledge $3^{\text {rd }}$ Ed (Upper Saddle, NJ: Prentice Hall, i989), Richard Feldman, 'Epistemological Duties,' in Paul K. Moser (ed.), The Oxford Handbook of Epistemology (Oxford UP, 2002), Richard Feldman, Epistemology (Upper Saddle, NJ: Prentice Hall, 2003), Sharon Ryan, 'Doxastic Voluntarism', in Jonathan Dancy, Ernest Sosa and Matthias Steup (eds.), A Companion to Epistemology (Malden, MA: Wiley-Blackwell, 2010), and Michael Pace, 'The Evidential Value of Moral Considerations,' forthcoming, Noûs. 
The second view is Optimism, which says that any set of evidence will, all things considered, justify at least one of the three doxastic attitudes toward a proposition. More precisely, Optimism says that for any set of evidence $\mathrm{E}$ and any proposition Q E will, all things considered, support either believing $Q$ disbelieving $Q$ or withholding judgment on $\mathrm{Q}$. Optimism is widely accepted in contemporary epistemology. ${ }^{2}$ Call the denial of Optimism Pessimism. Optimism should not be confused with Singularity, which says that any set of evidence will support no more than one attitude towards Q. Singularity does not bear on our present puzzle. The conjunction of Optimism and Singularity is equivalent to what is called Uniqueness in the literature. Uniqueness is the view that for any set of evidence $\mathrm{E}$ and any proposition $\mathrm{Q}, \mathrm{E}$ will support exactly one doxastic attitude toward Q - i.e. either belief, disbelief, or withholding, where the 'or' is understood exclusively. ${ }^{3}$ If Optimism is false, then so is Uniqueness.

The third view is a variant of Evidentialism, which says that, in the strictest sense, the epistemic propriety of a doxastic attitude is entirely a function of the subject's evidence. Epistemic propriety pertains to the intellectual ends of truth and knowledge, as opposed to moral or practical ends such as happiness or flourishing. The strictest sense of epistemic propriety restricts our attention to what attitude you should take toward a proposition at a given time, to the exclusion of diachronic considerations sensitive to what would promote broader, long-term intellectual goals, such as maximising the acquisition of true beliefs or knowledge over the long run, or improving cognitive habits. Evidentialism is popular among internalists and externalists alike. ${ }^{4}$ A weaker thesis than Evidentialism is Conditional Evidentialism, which says that if you have any evidence relevant to whether $\mathrm{Q}$ then the epistemic propriety of your doxastic attitude toward $\mathrm{Q}$ is entirely a function of your evidence. Conditional Evidentialism could be motivated by an attempt to accommodate innate knowledge within a broadly evidentialist framework.

However, in order to forestall reasonable but ultimately fruitless potential responses to the puzzle presented below, I will opt to work with an

${ }^{2}$ e.g., Earl Conee and Richard Feldman, Evidentialism (Oxford UP, 2004), ch. 4, and Roger White, 'Epistemic Permissiveness,' Philosophical Perspectives i9, pp. 445-59.

${ }^{3}$ See White, 'Epistemic Permissiveness,' Feldman, Epistemology, and Richard Feldman, 'Reasonable Religious Disagreements,' in Louise Anthony (ed.), Philosophers Without Gods (Oxford UP, 2007).

4 e.g., Juan Comesaña, 'Evidentialist Reliabilism,' Noûs, 44 (20I0), pp. 57I-6oo, Laurence BonJour, Epistemic Justification (Malden, MA: Blackwell, 2003), Conee and Feldman, Evidentialism, and in a different sort of way, Timothy Williamson, Knoweledge and Its Limits (Oxford UP, 2000). 
even weaker thesis yet, which takes into account William James's famous discussion ('The Will to Believe') of W.K. Clifford's moralistic version of evidentialism ('The Ethics of Belief'). For present purposes, we can understand James's point as follows: even in cases where there is some evidence relevant to whether $Q$ is true, if the evidence doesn't clearly decide the question, and there is little prospect of acquiring further evidence that would decide the question, and the choice between $Q$ and not- $Q$ is important for how you're going to live your life, then non-evidential considerations can affect the epistemic propriety of a doxastic attitude. Call such a situation Famesian, and let Restricted Evidentialism be the view that in all non-Jamesian situations, the epistemic propriety of a doxastic attitude is entirely a function of the subject's evidence. In short, aside from Jamesian situations, Evidentialism is true. Evidentialism entails Restricted Evidentialism, so if the latter is false, then so is the former. In presenting the puzzle, I will assume only that Restricted Evidentialism is true. (Actually, I will assume this only initially. Afterward I will suggest that the puzzle might persist even if we drop this assumption.)

\section{THE CASE}

\section{II.I. The stem}

One hundred of the world's most eminent mathematicians are gathered in a room for a meeting. In what is for them an act of extraordinary spontaneity, after finishing their official business they decide to inquire into a certain question nonchalantly raised by a member of their group. The question is whether a particular set of axioms, A, entails a particular claim, T. Let 'P' name the proposition that A entails T. For hours on end, they discuss whether P. They try to prove it. They try to disprove it. They think really hard. It's all great fun.

You wait outside, happy to perform the task assigned to you. You are to poll the Mathematicians as they file out of the room. You are interested in what they have to say, even though $\mathrm{P}$ is of purely theoretical interest to you, with absolutely nothing of practical importance to you riding on the question. This allows you to proceed with epistemically pure motives: you want to believe $\mathrm{P}$ if and only if $\mathrm{P}$ is true. You have enough mathematical training to understand the question under consideration. But you aren't an expert. You can't hear what the Mathematicians are saying as they deliberate. Indeed, you are completely ignorant of their deliberations. You know that their testimony will be sincere and informed by their considered expert judgment. 
The bell rings, signaling that the meeting is adjourned. The Mathematicians begin filing out. You stand ready with pen and paper - or, perhaps, with iPad and app - to record their respective verdicts. By stipulation, the Mathematicians' testimony exhausts your evidence relevant to $\mathrm{P}$.

\section{II.2. Branch I}

Each Mathematician reports that withholding judgment is the thing to do, and thereby advises you to withhold judgment. ${ }^{5}$ They report nothing more, nothing less. Call this branch of the case 'Mathematical Testimony I', or 'MTI' for short.

\section{II.3. Branch 2}

Each Mathematician reports that withholding judgment is not the thing to do, and thereby advises you to not withhold judgment. They report nothing more, nothing less. Call this branch of the case 'Mathematical Testimony 2', or 'MT2' for short.

\section{AN ASSESSMENT}

Let's consider what attitude you should take toward $\mathrm{P}$ in each branch of the case, the moment after compiling all the testimony. It's clear that you're not in a Jamesian situation, since nothing of practical importance turns on the matter, and your motivation is epistemically pure.

In the first branch, it seems obvious that you should withhold judgment on whether P. None of your evidence supports believing, so you shouldn't believe. And none supports disbelieving, so you shouldn't disbelieve. The remaining alternative is to withhold. Moreover, each Mathematician reports that withholding is the thing to do. So it seems that you should withhold. This fits a pattern: if all the Mathematicians had said that believing is the thing to do, then it would have been true that you should believe; and if all the Mathematicians had said that disbelieving is the

${ }^{5}$ If necessary, we can add that the Mathematicians are also trained Epistemologists, so that their advice to you carries more weight regarding what attitude you ought to take, in addition to their general estimation about what is (or is not) the attitude to adopt. I tend to think that their mathematical expertise is enough to underwrite the advice, and indeed that their general judgment that withholding is (or is not) the thing to do is probative for you. But others report that it seems to make a difference to how they consider the case, and it is harmless to add or subtract these details as we see fit. 
thing to do, then it would have been true that you should disbelieve. There is nothing puzzling in this.

In the second branch, it's not clear what you should do. None of your evidence supports believing, so you shouldn't believe. And none supports disbelieving, so you shouldn't disbelieve. The remaining alternative is to withhold. But the Mathematicians all say that withholding is not the thing to do! If all the Mathematicians had said that believing is not the thing to do, then it would have been true that you shouldn't believe. And had all the Mathematicians said that disbelieving is not the thing to do, then it would have been true that you shouldn't disbelieve. It stands to reason, then, that if all the Mathematicians say that withholding is not the thing to do, then you shouldn't withhold. This is puzzling.

\section{AN EPISTEMIC IMPASSE}

A genuine moral dilemma is a situation where an agent should do two incompatible things. ${ }^{6}$ Likewise a genuine epistemic dilemma would be a situation where a subject should adopt two incompatible doxastic attitudes toward a proposition. ${ }^{7}$ (If Singularity is true, then a genuine epistemic dilemma is impossible. But we aren't assuming Singularity presently.) A genuine epistemic impasse is similar to a dilemma, except that it occurs when you have no permissible option, as opposed to two conflicting required options. In an epistemic impasse, you shouldn't adopt any doxastic attitude toward $\mathrm{P}$, even though you're condemned to adopt one of them.

If the three assumptions discussed in the previous section are correct, then a genuine epistemic impasse is impossible. By Triad, you either believe, disbelieve or withhold $\mathrm{P}$, once you've considered it. By Optimism, your evidence must support taking at least one of those three attitudes. And since you're in a non-Jamesian situation with respect to $\mathrm{P}$, Restricted Evidentialism entails that nothing other than your evidence affects which attitude you should adopt (restricting ourselves to 'should' in the strict epistemic sense, of course); so if your evidence supports taking a doxastic

\footnotetext{
${ }^{6}$ Walter Sinnott-Armstrong, 'Moral Dilemmas and Incomparability,' American Philosophical Quarterly, 22 (I985), pp. 32I-29.

7 Douglas Odegard ('Resolving Epistemic Dilemmas,' Australasian Journal of Philosophy, 7I (I993), pp. I6I-8) and Earl Conee ('Against an Epistemic Dilemma,' Australasian Fournal of Philosophy, 72 (I994), pp. 475-8I) use 'epistemic dilemma' differently. Rather than understanding an epistemic dilemma analogously to a moral dilemma, by 'epistemic dilemma' they mean what I below call an 'epistemic impasse'. It doesn't matter to me whether we count epistemic impasses as a special kind of epistemic dilemma, or as a separate category all their own.
} 
attitude toward $\mathrm{P}$, then nothing overrides or undermines that, and you may do so all-things-considered.

But $\mathrm{MT}_{2}$ seems to be an example of a genuine epistemic impasse: in MT2, you should neither believe, disbelieve, nor withhold. So we must either revise the assessment of $\mathrm{MT}_{2}$, or we must reject at least one of Triad, Optimism and Restricted Evidentialism. If we reject Triad, then there is at least a fourth doxastic attitude or stance you can take toward a proposition. If we reject Optimism, then we're admitting the possibility that a set of evidence might justify neither belief, disbelief, nor withholding. If we reject Restricted Evidentialism, then we must accept that nonevidential factors can affect epistemic propriety, even in non-Jamesian situations; and this of course entails that we must reject Evidentialism too.

\section{DENYING RESTRICTED EVIDENTIALISM WON'T HELP}

Upon careful consideration, it seems that rejecting Restricted Evidentialism won't provide a solution to the puzzle. For even if we grant that non-evidential factors can and sometimes do affect epistemic propriety in non-Jamesian situations — as claimed by proponents of 'pragmatic encroachment' in epistemology, such as Jeremy Fantl and Matthew McGrath, Jason Stanley, John Hawthorne, and Michael Pace ${ }^{8}$ - there just doesn't seem to be any reason why this must be happening in MT2.

To motivate their view, pragmatic encroachers point to the role that knowledge and evidence play in practical reasoning, or in licensing action, or in setting a threshold of evidence or confidence required for full belief in a given context. But none of that seems to be occurring in $\mathrm{MT}_{2}$. In order for a solution along these lines to work, we would need to identify which ineliminable practical facts of the case might be relevant, and how they might relevantly affect the epistemic assessment. Otherwise, our puzzlement over $\mathrm{MT}_{2}$ will persist even if we give up Restricted Evidentialism.

\section{DENYING TRIAD WON'T HELP}

A tempting response to the puzzle is to deny Triad. To deny Triad is to deny that once you've considered a proposition, your only options are to

${ }^{8}$ Fantl and McGrath, Knowledge in an Uncertain World (Oxford UP, 2009), Stanley, Knowledge and Practical Interests (Oxford UP, 2005), Hawthorne, Knowledge and Lotteries (Oxford UP, 2004), and Pace, 'The Evidential Value of Moral Considerations.' 
adopt the attitude of believing, disbelieving or withholding. There seems to be at least a fourth alternative: adopt no attitude at all. You can withdraw from the proposition.

To believe is to take an attitude toward a proposition, an attitude of assent. To disbelieve is to take an attitude toward a proposition, an attitude of dissent. To withhold judgment is to take an attitude toward a proposition, an attitude of neutrality. In each case you end up with an attitude that has the proposition as its content. And in each case you, when you adopt the attitude in question, you incur a normative commitment to viewing that attitude as appropriate.

Withdrawing from a proposition isn't an attitude that takes the proposition as its content. Rather, it's a retreat from forming an attitude toward the proposition at all. In withdrawing, you don't incur a normative commitment to viewing any of the three attitudes as appropriate. Rather, you put yourself as near as you can get to the position you were in prior to considering the proposition in the first place.

Here is a metaphor to help better understand withdrawing. You approach a balance scale with the intent of getting on to it. You can step on to the right platform, you can step on to the left platform, and you can step on to the center. If you opt to occupy one of these three positions, then you commit yourself to the propriety of doing so. But if none of those three options seems good upon consideration, you also have the option of just not getting on the scale at all. You can continue standing there, poised to decide, but making no decision. And if none of the choices seems worthy when all is said and done, you can simply back away from the scale.

To entertain a proposition with the intent of adopting an attitude toward it is like approaching the scale. You can believe it (step on the right platform), you can disbelieve (step on the left platform), and you can suspend judgment (step on to the center). If you adopt one of those attitudes, then you commit yourself to the propriety of doing so. But if none of those three attitudes seems good upon consideration, you also have the option of just not forming any attitude at all. You can continue contemplating the evidence, poised to form an attitude, but forming no attitude. And if none of the three attitudes seems appropriate when all is said and done, you can simply withdraw from the proposition.

Just as there is a difference between stepping on to the center of the scale and backing away from the scale, so is there a difference between suspending judgment and withdrawing from a proposition. To suspend judgment on a proposition is a way of being engaged with it. To withdraw from a proposition is to disengage and move on. 
I was initially tempted by this way of handling the puzzle because the distinction between withholding and withdrawing seems faithful to the phenomenology of deliberation in my own case. There does seem to me to be an important difference between actively suspending judgment and withdrawing from a proposition. But further reflection reveals that while denying Triad might solve the version of the puzzle presented above, it won't help solve a closely related version, as I'll now explain.

Although withholding and withdrawing are importantly different, they're also similar in that they both count, in some sense, as remaining noncommittal on the truth value of P. Perhaps there are also other ways of remaining noncommittal on a question. Regardless of whether there are other ways, we can imagine a third way of completing the stem of the case from section 2.

\section{Branch 3}

Each Mathematician reports that remaining noncommittal is not the thing to do, and thereby advises you to not remain noncommittal. They report nothing more, nothing less. Call this branch of the case 'Mathematical Testimony 3', or 'MT3' for short.

Arguably in $\mathrm{MT}_{3}$ the Mathematicians' testimony discredits withdrawing just as much as it does withholding. So if you shouldn't withhold, then you shouldn't withdraw either. It's not immediately clear to me where this reasoning goes wrong, so I'm not entirely convinced that denying Triad will ultimately solve the puzzle.

Let Quartet be the view that there are only four doxastic responses belief, disbelief, withholding and withdrawing - and that once you've considered a proposition, there are, intellectually speaking, only four options open to you: you either believe it, disbelieve it, withhold judgment, or withdraw from it. If we group together withholding and withdrawing under the heading 'remaining noncommittal', then not remaining noncommittal is equivalent to either believing or disbelieving. So if the Mathematicians tell you that remaining noncommittal is not the thing to do, that is equivalent to telling you that either believing or disbelieving is the thing to do. But this isn't enough to favor either believing on the one hand, or disbelieving on the other. So it would be arbitrary to select between them. And selecting arbitrarily doesn't seem like it's something you should do. This makes it seem that denying Triad fails to successfully solve the puzzle.

The next section considers a miscellany of other responses to the puzzle. None of these responses presupposes a denial of Triad or Quartet, and are directed, in the first instance, at the initial statement of the puzzle, featuring $\mathrm{MT}_{2} . \mathrm{MT}_{3}$ will hereafter drop out of the discussion. 


\section{SOME OTHER RESPONSES TO THE PUZZLE}

The first response simply says that, despite initial appearances, you really should withhold in $\mathrm{MT}_{2}$, which makes for a simple solution. In reply, I find it difficult to accept that in a case where all the evidence directly indicates that withholding is not the thing to do, withholding is nevertheless the thing to do. We seem to be owed some explanation of why this should be so, especially since it would constitute a dramatic deviation from the effects of expert advice in other cases. Other things being equal, we think we should follow the experts' advice when they recommend: believing, disbelieving, withholding, not believing, and not disbelieving. Why would not withholding be any different? Perhaps it will be said that it's just a brute fact. I'm highly suspicious of this, but if it turns out to be true, then we will have learned something surprising about the limits of expert testimony's epistemic efficacy.

A second response derives from Earl Conee's evaluation of a different purported example of an epistemic impasse. Conee considers an example where you have good reason to believe $Q$ but you also have good reason to believe that your believing $Q$ will undermine the good reason you previously had to believe Q. For instance, you might have good reason to believe that you will win a footrace, but also good reason to believe that if you believe that you will win the footrace, then you will become overconfident and lose the footrace (see Odegard, 'Resolving Epistemic Dilemmas'). Says Conee, 'In these cases we do have epistemic reason to take another doxastic attitude. Epistemic reason to withhold judgment arises from a mere lack of epistemic reason to accept or deny' (Conee, 'Against an Epistemic Dilemma,' p. 479). In reply, notice that $\mathrm{MT}_{2}$ doesn't display this pattern, and so presents a completely new and independent reason for thinking that an epistemic impasse is possible. Moreover, we could grant Conee's point that the mere lack of evidence for believing or disbelieving provides you with a good reason to withhold. The problem with applying this to $\mathrm{MT}_{2}$ is that the Mathematicians' unanimous expert testimony threatens to outweigh this reason to withhold, so that, all things considered, it seems like you shouldn't withhold.

A third response says that, despite appearances, the Mathematicians aren't really giving you any advice in $\mathrm{MT}_{2}$. Their injunction to not withhold is inherently problematic, because it simply cannot be implemented. It thus fails to count as genuine advice, or at least fails to count as advice that affects which attitude you should adopt, and so fails to defeat the presumption in favor of withholding in the absence of any evidence for or against P. In reply, the injunction can be implemented. Believing or 
disbelieving would do the trick. (So would withdrawing.) There's nothing inherently problematic about the advice.

A fourth response doesn't claim that the Mathematicians' advice is inherently problematic, but instead says that, in the given context, it can't be taken seriously if they know that you're in an 'evidential vacuum,' such that neither believing nor disbelieving is appropriate, and their advice is all the evidence you'll have relevant to P. In reply, I stipulate that the Mathematicians know no such thing. We may even suppose that they reasonably but falsely believe that your prior evidence makes it very difficult to judge whether you should believe or withhold judgment. (I could without loss have said 'disbelieve or withhold judgment' instead.) Now if the experts advise against withholding, they would think that they're making your choice easy.

A fifth response says that in cases such as MT2, you may adopt whatever attitude would most please you, or whatever attitude would best promote your practical goals, or some other such suggestion which allows non-evidential factors to help decide the epistemic question, beyond what James envisioned. In reply, I stipulate that you have no preference among the three attitudes on this question, and that your practical goals would be promoted just as well by adopting any of the three attitudes. Your only concern in the case is to adopt the, or at least an, appropriate doxastic attitude toward P. Or if that isn't enough, I stipulate that your only concern is to adopt an attitude supported by the evidence, if there is one.

\section{GONGLUSION}

None of the proposed solutions to the puzzle seems fully satisfactory. I, for one, am left puzzled. ${ }^{9}$

University of Waterloo, Canada

${ }^{9}$ For helpful feedback and discussion on this material, I'm happy to thank David Alexander, E.J. Coffman, Juan Comesaña, Earl Conee, Dave DeVidi, Joseph Haley, Ali Hassan, Nathan Haydon, Mark Huston, Brent Madison, Patricia Marino, Rhys McKinnon, Jesse Onland, Navid Poulad, Ted Poston, Daniel Resnick, Andrew Rotondo, Bruce Russell, Paul Simard-Smith, Atul Sivaswamy, Richard Turri, Natascha Van Lieshout, Matt Zuckero, and especially Angelo Turri. This research was supported by the Social Sciences and Humanities Research Council of Canada. 